\title{
Intra OP Predictors of Prolonged Invasive Mechanical Ventilation and Hospital Stay after Off Pump Coronary Artery Bypass Grafting
}

\author{
Dr. CS Ahluwalia ${ }^{1}$, Dr. Shibu Sasidharan ${ }^{2 *}$, Dr. Anish K Adya ${ }^{3}$, Dr. Harpreet Singh Dhillon ${ }^{4}$ \\ Dr. Babitha $\mathbf{M}^{5}$
}

${ }^{1}$ MD, Associate Professor, Consultant Anaesthesia, MG Med, HQ MB Area, Jabalpur, MP.

${ }^{2}$ Assistant Professor, MD, DNB, MNAMS; HOD (Anaesthesia); Dept of Anaesthesia and Critical care, Level 3 Hospital, Goma.

${ }^{3}$ DNB (Anaesthesia), Command Hospital, Chandimandir.

${ }^{4} \mathrm{MD}$ (Psychiatry), Reader, Level 3 Hospital, Goma.

${ }^{5}$ DMRD, Consultant Radiodiagnosis, Department of Radiodiagnosis\& Imaging, Ojas Hospital, Panchkula, Haryana.

*Corressponding Author: Dr. Shibu Sasidharan, Assistant Professor, MD, DNB, MNAMS; HOD (Anaesthesia); Dept of Anaesthesia and Critical care, Level 3 Hospital, Goma.

\section{BACKGROUND}

The last decade has seen significant advances in the treatment of coronary artery disease (CAD). Drug eluting stent and off pump CABG (OPCAB) are emerged as the alternative methods of coronary revascularization that avoids the use of cardiopulmonary bypass (CPB). The avoidance of CPB during OPCAB has made the operation equivalent to any other major non cardiac surgical procedure. This has led the cardiac anaesthesiologist to believe elective post operative ventilation may not always be necessary in these patients.

Prolonged mechanical ventilation (PMV), also known as delayed extubation, is an important complication following cardiovascular surgeries. Although occurs in only 3 to $9.9 \%$ of patients, it may be associated with considerable morbidity and mortality(1-3). A significant number of these patients will undergo tracheostomy(4).Patients who experience delayed extubation will have longer intensive care unit (ICU) and hospital stay, higher treatment cost and lower quality of life(5-8). Furthermore, it may lead to undue occupation of ICU beds leading to a lengthening of waiting list and cancellation of other elective cardiac operations.

PMV is most commonly defined as ventilation $\geq 24 \mathrm{hrs}$ (Society of Thoracic Surgeons (STS) score), but has been variously defined as a cumulative duration of mechanical ventilation for $\geq 6 \mathrm{hrs}, \geq 8 \mathrm{hrs}, \geq 24 \mathrm{hrs}$, $\geq 72 \mathrm{hrs}$, or as long as $\geq 14$ days (9-11). Majority of patients in the intensive care unit (ICU) are ventilated for few hours, this study mainly concentrates on a group of patients who need ventilation for more than 24 hours.

We defined PIMV as cumulative ventilation time of more than 24 hours believing that 24 hours is a sufficiently long time for hemodynamic stabilization and to off-set the deleterious effects of surgery. Moreover 24-hours cut-off limit for prolonged ventilation is also used in the STS database. Previous data have shown that mortality increases significantly in patients staying for $\geq 7$ days in the ICU after cardiac surgery(12).

There are many complications associated with PMV, including vocal cord granulomas and ulcerations (13), oxygen toxicity, and local inflammation(14). Patients with prolonged mechanical ventilation experience worse physiological outcome due to atelectasis and intrapulmonary shunting(15). Respiratory failure and pneumonia have been traditionally the leading causes of postoperative complications(16).

The clinical advantages of early extubation are mainly that it reduces the possibility of adverse effects of positive pressure ventilation and minimizes associated patient discomfort, potentially decreases the incidence of infection and facilitates early ambulation. The early extubation itself helps to reduce ICU stay and hospitalization cost(1). 
Intra OP Predictors of Prolonged Invasive Mechanical Ventilation and Hospital Stay after Off Pump Coronary Artery Bypass Grafting

Recent advances in anaesthesia, surgical techniques, myocardial protection, extracorporeal perfusion techniques, critical care protocols and improved perioperative management all had contributed to the success of early extubation and shorter hospitalization in the cardiac surgical population(17).In the last years cardiac anaesthesia has fundamentally changed from high-dose opiate based technique to a more balanced approach using moderate dose narcotics, inhalational agents, and shorter acting narcotics(18).

Thus, mainly due to financial constraints, the focus of cardiac anaesthesia started shifting in the early 1990 's to lower dose opioids, earlier extubation and decreased ICU stay. This came to be labeled as 'Fast Track Cardiac Anaesthesia' (FTCA)(19).

The aim of this study was to analyze intraoperative characteristics risk factors that associated with prolonged mechanical ventilation and hence intensive care unit and hospital stay after off pump coronary artery bypass grafting. The risk factors included duration of surgery, number of grafts, and transfusion requirement during surgery.

\section{MATERials \& MethodS}

\section{Study Area}

Tertiary Care teaching hospital in India.

\section{Study Population}

Present study was conducted on 140 patients aged more than 18 years, of either sex, who were scheduled for elective isolated off pump coronary artery bypass grafting.

\section{Study Design}

A Prospective, cross sectional, observational study.

\section{Sample Size}

The percentage of patients undergoing off pump CABG in prolonged ventilation is 6\%(3 to $9 \%$ ), assuming the absolute precision is $4 \%$ and $95 \%$ confidence interval the minimum required sample size is 135

\section{Time Frame of the Study}

Study was done from Jan 1st 2017 to Dec 31st 2017.

\section{METHODOLOGY}

- As a standard policy of the unit all patients were explained the details of surgery and informed consent was taken.
- Anaesthesia and analgesia were standardized for all patients as per our institutional practice.

- All patients included in the study were premedicated with tablet Alprazolam $0.25 \mathrm{mg}$ and pantoprazole $40 \mathrm{mg}$ orally at night before surgery and they were kept nil oral $8 \mathrm{hrs}$. before surgery.

- Next day on arrival of patients in the operating room preoperative risk factors were noted, patients were induced with midazolam 0.1 $\mathrm{mg} / \mathrm{kg}$, fentanyl $5 \mu \mathrm{g} / \mathrm{kg}$, etimodate $0.1 \mathrm{mg} /$ $\mathrm{kg}$ and pancuronium $0.1 \mathrm{mg} / \mathrm{kg}$ and patients were intubated with appropriate size cuffed endotracheal tube under direct laryngoscopy and patients were ventilated with volume control ventilation. Ventilator settings were managed according to EtCO2 and ABG status which is done every hour and whenever necessary.

- Anesthesia was maintained with inhalational anesthetic isoflurane (1-2\%). Analgesia and muscle relaxation was maintained with fentanyl $1 \mathrm{mg} / \mathrm{kg}$ bolus and pancuronium $0.02 \mathrm{mg} / \mathrm{kg}$ bolus respectively every hour and whenever required.

- ECG, ST segment, Sp02, EtCO2, invasive BP, CVP, FiO2, anesthetic gases, nasopharyngeal temperature and urine output were monitored continuously.

- Norepinephrine $(40 \mu \mathrm{g} / \mathrm{ml}$ dilution $)$ and nitroglycerin (NTG) $(1 \mathrm{mg} / \mathrm{ml}$ dilution) infusion were used depending up on blood pressure. Epinephrine $(40 \mu \mathrm{g} / \mathrm{ml}$ dilution) and dobutamine $(5 \mathrm{mg} / \mathrm{ml})$ also were used whenever necessary. Sudden drop in blood pressure was managed with 50 to $100 \mu \mathrm{g}$ bolus of phenylephrine.

- Anticoagulation while grafting was done with unfractionated heparin $2 \mathrm{mg} / \mathrm{kg}$ bolus and $1 \mathrm{mg} /$ kg top up doses every hour. ACT while grafting maintained above 250. At the end of grafting anticoagulation was reversed with protamine 1:1 ratio.

- Blood transfusion was done when patient was hemodynamically unstable due to blood loss and /or hematocrit was less than 25 in ABG. Preoperative blood transfusion was not included in the analysis. 
Intra OP Predictors of Prolonged Invasive Mechanical Ventilation and Hospital Stay after Off Pump Coronary Artery Bypass Grafting

\section{SuRgical TECHNIQUE}

All of our study patient's CABG had been performed by the same groups of surgeons. The standard approach was median sternotomy. Left internal mammary artery (LIMA) and Reversed Saphenous Vein Graft (RSVG) were harvested. Our usual grafting was LIMA to LAD and RSVG to OM, RCA, PDA and others.

After completing surgery patients were shifted to ICU continued ventilation with VCV and monitoring was continued with ECG, ST segment, SpO2, EtCO2, invasive $\mathrm{BP}, \mathrm{CVP}$, nasopharyngeal temperature, urine output and chest tube drainage. Analgesia was maintained with fentanyl infusion 0.5 to $1 \mu \mathrm{g} / \mathrm{kg} /$ hour.\}

Once the patient is warm (temp> 35.50C), awake, conscious and cooperative, haemodynamically stable with minimal or no inotrope support and achieved good clinical neuromuscular recovery and chest tube draining is less than $50 \mathrm{ml} / \mathrm{hr}$., ventilator weaning was started with synchronized intermittent mandatory ventilation. Then patients were put on CPAP mode after slowly reducing the rate up to 8breath/minute in SIMV. Patients were extubated if arterial oxygen tension was $>70 \mathrm{~mm} \mathrm{Hg}$, arterial carbon dioxide tension was $<45 \mathrm{~mm} \mathrm{Hg}$ and $\mathrm{pH}$ between7.35 to7.45 on CPAP with fractional inspired oxygen concentration less 0.5 , for half an hour.And patients were extubated once they achieve extubation criteria. Those patients who could not be extubated in more than 96 hours and were expected to need PMV underwent surgical tracheostomy.

\section{Statistical Methods}

Patients were divided two groups GROUP A and GROUP B depending up on duration of mechanical ventilation.

GROUP A: Post-operative mechanical ventilation $\leq 24$ hours.

GROUP B: Post-operative mechanical ventilation $>24$ hours (PMV group)

Student's t-test or Mann Whitney test was used for to find the significance difference between the number of vessels grafted \& duration of surgery and its expressed as mean and standard deviation.

Chi square or fisher exact test was used for to find the association between transfusion and duration of ventilation and its expressed as frequency and percentage.

$\mathrm{p}<0.05$ considered as statistically significance.

\section{RESULT}

There were $121(86.43 \%)$ male patients and $19(13.57 \%)$ female patients. Among all 27(19.28\%) patients were associated with post-operative mechanical ventilation $>24$ hours (GROUP B, PMV group). Remaining 113 patients were extubated $\leq$ 24 hours (GROUP A). Out of 27 patients in prolonged mechanical ventilation group, 3(11.11\%) patients underwent tracheostomy. The results of the study are presented as Tables 1-4.

Table 1. Mechanical Ventilation, Icu Stay, and Hospital Stay

\begin{tabular}{|c|c|c|c|}
\hline PARAMETER & GROUP A(n=113) & GROUP B(n=27) & P \\
\hline Duration of MV(hours) & $12 \pm 3.34$ & $33 \pm 8.13$ & $0.0001(\mathrm{~S})$ \\
\hline Duration of ICU stay(hours) & $24 \pm 5.8$ & $48 \pm 12.9$ & $0.0001(\mathrm{~S})$ \\
\hline Duration of Hospital (days) & $5 \pm 0.99$ & $7 \pm 1.75$ & $0.0001(\mathrm{~S})$ \\
\hline
\end{tabular}

Table 2. Duration of Surgery

\begin{tabular}{|c|c|c|c|c|}
\hline \multicolumn{2}{|c|}{ GROUP A } & \multicolumn{2}{c|}{ GROUP B } & \multirow{2}{*}{ P } \\
\cline { 1 - 3 } MEAN & SD & MEAN & SD \\
\cline { 1 - 3 } & 0.89 & 4.55 & 0.86 & \\
\hline
\end{tabular}

Table 3. Number of Vessels Grafted

\begin{tabular}{|c|c|c|c|c|}
\hline \multicolumn{2}{|c|}{ GROUP A } & \multicolumn{2}{c|}{ GROUP B } & P \\
\hline MEAN & SD & MEAN & SD & 0.32 \\
\hline 2.58 & 0.86 & 2.81 & 1.66 & \\
\hline
\end{tabular}

Archives of Anesthesiology V3 . I1 . 2020 
Intra OP Predictors of Prolonged Invasive Mechanical Ventilation and Hospital Stay after Off Pump Coronary Artery Bypass Grafting

Table 4. Transfusion

\begin{tabular}{|c|c|c|c|}
\hline TRANSFUSION & GROUP A & GROUP B & P \\
\hline INTRA-OP & $10(8.84 \%)$ & $4(14.81 \%)$ & 0.354 \\
\hline POST-OP & $16(14.15 \%)$ & $6(22.22 \%)$ & 0.327 \\
\hline
\end{tabular}

\section{DiscUSSION}

The use of off-pump coronary artery bypass surgery (OPCAB) for surgical candidates deemed to be at high risk has become increasingly popular as a result of evolving evidence showing outcome and cost benefits (18-25). High-risk patients, such as the elderly and women, appear to benefit, with lower rates of mortality and other adverse events with OPCAB, compared with conventional on-pump coronary artery bypass surgery (ONCAB) (26-27). In fact, the female sex has disappeared as a risk factor from studies of OPCAB, which demonstrate reduced mortality, respiratory complications and lengths of hospital stay for women $(11,12)$. It also appears that high-risk patients may have lower rates of adverse outcomes with the use of OPCAB.

In this study, we have studies the intra-op factors affecting the duration of stay and prolonged mechanical ventilation in patients undergoing an OPCAB. There are limited studies done on the OPCAB, in respect to the factors studied in this research, in comparison to ONCAB. Several randomized controlled trials (RCTs) have been conducted that have either favored on-pump CABG or have failed to show a significant difference in outcomes between the two techniques. However, these RCTs have been fraught with claims that they do not represent the majority of patients undergoing $\mathrm{CABG}$ in real world practice. Therefore, assessment of the benefits and drawbacks of each technique through observational and registry studies would be more representative of patients encountered in daily practice. The present review examined and established that the duration of surgery, number of grafts, and transfusion requirement during surgery were not strong predictors of prolonged medical stay and care, and thus other factors in pre-op and postop need to be considered. Strategies to delineate the patients at risk and to modify those risk factors by prophylactic measures should probably lead to a lower incidence of prolonged mechanical ventilation in patients undergoing isolated off pump CABG surgery.
However there were a few limitations in the study:

The observational nature of the study, the relatively small patients' sample which may affect the power of the study by increasing the chance of type II error (false negatives) and that it is a single centre study.

Most of the previous studies which we have used for reference were on "ON PUMP CABG" and only few studies were on off pump CABG. Our study tried to find risk factors for PMV in "OFF PUMP CABG" in the same way of previous studies.

We included only elective isolated off pump CABG cases but as per previous studies urgent surgery, was one of the reason for PMV. We failed to evaluate the same.

\section{CONFLICTS OF INTEREST}

The authors have none to declare.

\section{ACKNOWLEDGEMENT}

The authors would like to thank all the subjects who consented to participate in this study.

\section{REFERENCES}

[1] Arom KV, Emery RW, Petersen RJ, Schwartz M. Cost effectiveness and predictors of early extubation. Ann Thoracic Surg. 1995;60:127-32. doi : 10.1016/s00034975(95)003568.

[2] Walthall H, Robson D, Ray S. Do any preoperative variables have an effect on the timing of tracheal extubation after coronary artery bypass graft surgery? Heart Lung. 2001;30:216-24. Doi:10.1016/s00034975(95)003568.

[3] Ingensoll G, Grippi M. Preoperative pulmonary status and postoperative extubation outcome of patients undergoing elective cardiac surgery. Heart Lung. 1991;20:137-43.

[4] Walthall H, Ray S, Robson D. Does extubation result in homodynamic instability in patients following coronary artery bypass grafts? Intensive Crit Care Nurse. 2001;17:286-93.doi: 10.1054/iccn.2001.1598. 
Intra OP Predictors of Prolonged Invasive Mechanical Ventilation and Hospital Stay after Off Pump Coronary Artery Bypass Grafting

[5] Reddy SL, Grayson AD, Griffiths EM, DM, Rashid A. Logistic risk model for prolonged ventilation after adult cardiac surgery. Ann Thorac Surg. 2007;84:528-36. doi:10.1016/j. athoracsur.2007.04.002.

[6] Pappalardo F, Franco A, Landoni G, Cardano P, Zangrillo A, Alfieri O. Longterm outcome and quality of life of patients requiring prolonged mechanical ventilation after cardiac surgery. Eur J Cardiothorac Surg. 2004;25:548-52. doi: 10.1016/j.ejcts.2003.11.034.

[7] Ascione R, Lloyd CT, Underwood MJ, Lotto AA, Pitsis AA, Angelini GD. Economic outcome of off pump coronary artery bypass surgery: a prospective randomized study. Ann Thorac Surg. 1999;68:2237-42. doi:10.1016/ s00034975(99)011236.

[8] Rajakaruna C, Rogers CA, Angelini GD, Ascione R. Risk factors for and economic implications of prolonged ventilation after cardiac surgery. J ThoracCardiovasc Surg. 2005;130:12707. doi:10.1016/j.jtcvs.2005.06.050.

[9] Branca P, McGaw P, Light R. Factors associated with prolonged mechanical ventilation following coronary artery bypass surgery. Chest. 2001;119:537-46. doi: 10.1378/ chest.119.2.537.

[10] Serrano N, García C, Villegas J, Huidobro S, Henry CC, Santacreu R. et al. Prolonged intubation rates after coronary artery bypass surgery and ICU risk stratification score. Chest. 2005;128:595601. doi:10.1378/chest.128.2.595.

[11] Habib RH, Zacharias A, Engoren M. Determinants of prolonged mechanical ventilation after coronary artery bypass grafting. Ann Thorac Surg. 1996;62:1164-71.doi: 10.1016/00034975(96)005656.

[12] Solomon NW, Page S, Bigelow JC, Krause AH, Okies JE, Metzdorff MT. Coronary artery bypass grafting in elderly patients. Comparative results in a consecutive series of 469 patients older than 75 years. J ThoracCardiovascSurg 1991; 101: 209-218

[13] Kastanos N, EstopáMiró R, Marín Perez A, Xaubet Mir A, Agustí-Vidal A Laryngotracheal injury due to endotracheal intubation: incidence, evolution, and predisposing factors. A prospective longterm study Crit Care Med. 1983; 11: 362-367.

[14] Sackner MA, Hirsch J, Epstein S. Effect of cuffed endotracheal tubes on tracheal mucous velocity. Chest.1975; 68: 774-777.

[15] Gass GD, Olsen GN: Preoperative pulmonary functional testing to predict postoperative morbidity and mortality. Chest 1986; 89: 127 175

[16] Cheng DCH, Karski J, Peniston C, et al. Morbidity outcome in early versus conventional tracheal extubation after coronary bypass grafting; a prospective randomized controlled trial. J ThoracCardiovascSurg 1996; 112: 755-764

[17] Herlihy JP, Koch SM, Jackson R. Course of weaning from prolonged mechanical ventilation after cardiac surgery. Texas Heart Institute Journal 2006; 33(2): 122-129.

[18] Kaplan JA, Cheng CH, Brainbridge D, et al. Kaplan's cardiac anesthesia. 5th ed. Saunders, Elsevier 2006; Ch: 32: 1043-1059.

[19] Silbert B S; Myles P S. Is fast-track cardiac anesthesia now the global standard of care? AnesthAnalg 2009108:689-691

[20] Hart JC. A review of 140 Octopus off-pump bypass patients over the age of seventy: Procedure of choice? Heart Surg Forum. 2001;4(Suppl 1):S24-9. [PubMed] [Google Scholar]

[21] Kihara S, Shimakura T, Tanaka SA, et al. Initial experience with off-pump coronary artery bypass grafting. Heart Vessels. 2001;16:9-11. [PubMed] [Google Scholar]

[22] Lancey RA, Soller BR, Vander SalmTJ. Off-pump versus on-pump coronary artery bypass surgery: A case-matched comparison of clinical outcomes and costs. Heart Surg Forum. 2000;3:277-81. [PubMed] [Google Scholar]

[23] Lee JH, Abdelhady K, Capdeville M. Clinical outcomes and resource usage in 100 consecutive patients after off-pump coronary bypass procedures. Surgery. 2000;128:548-55. [PubMed] [Google Scholar] 
Intra OP Predictors of Prolonged Invasive Mechanical Ventilation and Hospital Stay after Off Pump Coronary Artery Bypass Grafting

[24] Patel NC, Grayson AD, Jackson M, et al. North West Quality Improvement Programme in Cardiac Interventions The effect off-pump coronary artery bypass surgery on in-hospital mortality and morbidity. Eur J Cardiothorac Surg. 2002;22:255-60. [PubMed] [Google Scholar]

[25] Petro KR, Dullum MK, Garcia JM, et al. Minimally invasive coronary revascularization in women: A safe approach for a high-risk group. Heart Surg Forum. 2000;3:41-6. [PubMed] [Google Scholar]
[26] Puskas JD, Wright CE, Ronson RS, Brown WM, III, Gott JP, Guyton RA. Clinical outcomes and angiographic patency in 125 consecutive offpump coronary bypass patients. Heart Surg Forum. 1999;2:216-21. [PubMed] [Google Scholar]

[27] Puskas JD, ThouraniVH, Marshall JJ, et al. Clinical outcomes, angiographic patency, and resource utilization in 200 consecutive off-pump coronary bypass patients. Ann Thorac Surg. 2001;71:147783. 1483-4. [PubMed] [Google Scholar]

Citation: Dr. CS Ahluwalia, Dr. Shibu Sasidharan et al. Intra OP Predictors of Prolonged Invasive Mechanical Ventilation and Hospital Stay after Off Pump Coronary Artery Bypass Grafting. Archives of Anesthesiology. 2020; 3(1): 14-19

Copyright: (C) 2020 : Dr. CS Ahluwalia, Dr. Shibu Sasidharan et al. . This is an open access article distributed under the Creative Commons Attribution License, which permits unrestricted use, distribution, and reproduction in any medium, provided the original work is properly cited. 